\title{
Decision model to control water losses in distribution networks
}

\author{
Marcele Elisa Fontana ${ }^{\mathrm{a} *}$, Danielle Costa Morais ${ }^{\mathrm{a}}$ \\ anniversidade Federal de Pernambuco, Recife, PE, Brasil \\ *marcelelisa@gmail.com
}

\begin{abstract}
The losses in the urban water supply networks have become a growing concern. There are several alternatives for the quantification, detection and monitoring of water losses. However, in general, water companies have budgetary and other constraints that hinder implementation. Therefore, this paper presents a model to aid the selection of a subset of preventive maintenance actions to control water losses while accounting for the water companies' restrictions. The model combines an additive multi-attribute value analysis by applying the SMARTER method to evaluate alternatives with Integer linear Programming (ILP). The model shows to be efficient in order to achieve a portfolio of preventive maintenance actions, particularly when the decision maker considers that, there is a compensation for attribute evaluations.
\end{abstract}

Keywords

Water distribution network. Water loss control. Multi-attribute. SMARTER method. Integer linear programming.

\section{Introduction}

Water is a valuable resource, critical to economic development (Horne, 2013). However, developing countries worldwide face significant challenges in managing increasing demand for urban water because of industrialization, urbanization and the potential impacts of global warming on freshwater supply (Araral \& Wang, 2013). Moreover, not all water produced reaches the customers to generate revenue for water companies. Instead, a significant portion of it is lost, due to leakage from water mains and unauthorized water use (Wu et al., 2010). The loss of treated water occurs by leakages and overflows from the pressurized pipes and fittings in water undertaker distribution systems and customers' private supply pipes (Lambert, 1994). Increasingly, water loss via leakage is acknowledged as one of the primary challenges facing water distribution system operations. The consideration of water loss over time as systems age, physical networks grow, and consumption patterns mature should be an integral part of effective asset management (Giustolisi et al., 2008). For this, the use of planning and management tools for water management in urban environments became a promising area of study (Tabesh et al., 2014).

With the international trends increasingly leaning toward susceptibility, economic efficiency, water shortages and protection of the environment, the problem of water loss from supply systems is of major interest world-wide, as it affects water companies and their customers (Covas et al., 2005; Holnicki-Szulc et al., 2005; Puust et al., 2010; Wu, 2009). Moreover, the demand for water is rising steadily (Mesquita \& Ruiz, 2013).

Historically, when there are high losses in the supply system, it becomes more economical to improve the system, ration water use and perform continuous maintenance to keep the system efficient than to build new systems, which certainly will lead to high installation costs and environmental impact. lssues relating to loss of water must be treated and managed with preventive measures aimed to improve the procedures for maintenance and operation of networks (Trojan \& Morais, 2012). 
Many studies have been done with the aim of reducing leaks and improving services (Abu-Shams \& Rabadi, 2003). However, the leakage reduction problem as a whole is complex and requires coordinated actions in different areas of the water network management, such as the direct detection and repair of existing leaks, general pipe rehabilitation programs and operational pressure control (Morais \& Almeida, 2007). While pipes are designed and constructed to maintain their integrity, it is difficult to avoid leakages completely in a pipe system during its entire lifetime. Often, accurate leak detection, which enables a quick response, is necessary to minimize damage (Wang et al., 2002).

There are different solutions for leakage reduction in water distribution networks. One technique for leakage reduction is pressure management, which considers the direct relationship between leakage and pressure (Nazif et al., 2010; Nicolini \& Zovatto, 2009). This is because pipe pressure affects leakage in a number of ways, and pressure management can realize a substantial reduction in leakage. The lower the pressure, the lower the frequency of pipe breaks. Additionally, frequent pressure fluctuations may cause fatigue failure in pipes, particularly with plastic pipes (Hunaidi \& Wang, 2006).

A water distribution system (WDS) is a complex network of interconnected pipes that delivers water from the source(s) to consumers. In addition to the pipes, which are major components, a WDS involves mechanical and hydraulic control elements such as pumps, storage tanks, reservoirs, regulators, valves and joints (Gheisi \& Naser, 2013). Therefore, there are different types of leaks, including service line leaks and valve leaks. However, in most cases, the largest portion of water that is unaccounted for is lost through leaks in supply lines. There are many possible causes of leaks, and often a combination of factors leads to their incidence. The factors that may contribute to leaks in pipes include the following: the material, composition, age, and joining methods of the distribution system components; corrosion and deterioration of pipes; elevated pressures in the water network; soil characteristics and movement. Water conditions, including the temperature, velocity, and pressure, are also a factor (Arreguín-Cortes \& Ochoa-Alejo, 1997).

The consequences of unpredicted, large-scale leakages in operating water networks can be highly serious. Therefore, there is a need for an automatic monitoring system that is able to detect and pinpoint leaks in incipient stages (Holnicki-Szulc et al., 2005). Monitoring is one of the most important steps for advanced control of complex dynamic systems. Precise information about the systems' behavior, including fault indication, enables efficient control (Duzinkiewicz et al., 2008).
Moreover, inadequate maintenance of water supply systems has serious consequences. Especially these days when society is faced with severe water shortage scenarios, the search by possible solutions to minimize this problem through a specific strategy for the management of losses is necessary (Morais \& de Almeida, 2007).

According to Trojan \& Morais (2012), problems encountered in the maintenance management of water supply are indicated by the lack of decision support models that give a manager an overview of the system. From this statement, this paper aims to analyze preventative actions related to maintenance of the water supply network to control water losses and build a portfolio of the best actions.

However, there are many possible actions, with each exhibiting distinct characteristics. Thus, to assess which of these alternatives will be adopted, it is necessary to survey attributes that will evaluate alternatives according to the companies' needs. However, these attributes often are conflicting in their cost versus benefits. Therefore, it is also important to study approaches that are able to handle this type of scenario, such as with multi-attribute approaches.

Moreover, this type of problem usually has some constraints. These restrictions, in general, can be budgetary and/or technical. Most multi-attribute methods do not account for restrictions on the deployment of alternatives. From the literature, there is the PROMETHEE V method (Preference Ranking Organization Method for Enrichment Evaluations), which carries out this function. It uses the net flow of PROMETHEE 11 method as the coefficient for each alternative in the objective function and applies integer linear programming (Lopez \& Almeida, 2013; Fontana \& Morais, 2013). However, this method does not consider trade-offs between attributes.

Thus, this paper proposes a model that uses an additive multi-attribute value method to evaluate the alternatives based on different attributes that can be considered, thereby making possible to analyze costs versus benefits, for instance. In addition, as the Water Companies normally present constrains on the implementation of alternatives, this model proposes also the use of an integer linear programming, in order to consider those constrains and to select a subset of viable preventive maintenance actions to control water losses.

This paper is organized as follows: Section 2 presents the definition of water losses in water supply systems - WSS. In section 3, the proposed model is described, and a simulated case is presented to illustrate the application of this model. Finally, concluding remarks are made. 


\section{A brief overview}

\subsection{Water supply systems}

In general, a water distribution network can be divided into different subsystems, each of which may present similar pipe conditions and water consumption characteristics (Wu et al., 2010). Leakages or water loss is modeled as demand in addition to the recorded demand that can be calculated and assigned by different loading methods using customer meter information (Wu et al., 2003).

Currently, the need for conservative water use is more pressing than ever because the stressful climate change conditions force water utilities to consider applying effective Non-Revenue Water reduction strategies (Kanakoudis \& Tsitsifli, 2014). In this sense, the real losses are physical losses due to leakages from the supply network, while the apparent losses are not physical, but rather financial losses that lead to decreased revenue. In other words, the apparent losses consist of water volumes that are withdrawn from the network and consumed by users, but are not paid for (Fontanazza et al., 2012). In this way, the reduction of non-physical losses allows for increased financial revenue, which increases the efficiency of the service provider, while the reduction of physical losses reduces production costs by reducing energy consumption; this way it is possible to improve the use of existing resources to increase supply without, necessarily, expanding the production system.

The International Water Association has been advocating and promoting four basic leakage management activities for leakage reduction, namely: (i) pressure management; (ii) active leakage control; (iii) speed and quality of repairs and pipe asset management; (iv) maintenance and renewal (Charalambous et al., 2014). According to Hunaidi et al. (2004) the management of leakage comprises four main components: (i) quantifying the total water loss, (ii) monitoring of leakage, (iii) locating and repairing leaks, and (iv) pipe pressure management.

On the other hand, the most papers regarding pressure management use the pressure as a means to quantify, monitor or detect the water leak. Thus, according to Puust et al. (2010), most of the leakage management methods, developed so far, can be broadly classified, as follows: (i) leakage assessment methods that focus on quantifying water loss; (ii) leakage detection methods primarily concerned with the detection of leakage hotspots; and (iii) leakage control models that focus on the effective control of current and future leakage levels.

\subsubsection{Leakage assessment methods}

Quantification of the total amount of water lost is achieved by conducting a system-wide water audit, which is known internationally as a water balance. Audits provide a valuable overall picture of the various components of consumption and loss, which is necessary for assessing a utility's efficiency regarding water delivery, finances, and maintenance operations. Additionally, water audits are necessary for planning other leakage management practices (Hunaidi et al., 2004).

There are different solutions for leakage reduction in water distribution networks. Some of them are structural solutions such as using pressure reducing valves or pump stations in appropriate locations. There are also non-structural solutions, which are tackled through management schemes, are very effective, and require no capital investment (Nazif et al., 2010).

\subsubsection{Detection and location of leakage}

If undetected, leaking pipes can jeopardize the integrity of the drinking water distribution system and lead to serious operational problems. For example, leaks inflate downstream demands, increase energy expenditures, erode utility revenue, and compromise water quality (Buchberger \& Nadimpalli, 2004). Leak detection is now considered as "a money-saving expense", and systematic leakage control programs are implemented by operators for both the immediate and long-term goals of operating an efficient water system (Ferrante \& Brunone, 2003).

Leakage detection activities may be classified in two groups: reactive and proactive. Water company personnel perform reactive leak detection once it is determined that a sufficiently serious problem has developed. Problems can be identified via customer contacts or other information. Several research and development projects have explored the potential for leak location by searching for deviations in pressure signals across multiple pressure monitoring points (Mounce et al., 2010).

Proactive leak detection is based on the subdivision of distribution systems into discrete zones by the permanent closure of valves and the measurement of the flows into each zone. By monitoring average night flows, unusual changes in water volumes can be detected. The identification and quantification of distribution losses in this way relies on accurate estimation of the expected nightly flows (McKenzie \& Seago, 2005).

Currently, leak detection and location techniques can be classified as (1) direct observation methods and (2) inference methods. Direct observation methods 
are based on the external or internal inspection of pipe characteristics by visual observation or using appropriate equipment. Inference methods rely upon the monitoring of internal pipe parameters and the application of a mathematical model that, based on the data collected, carries out leak detection (Covas et al., 2005).

\subsubsection{Leakage control}

The pipe breaks can be very expensive due to the service interruption, cost of repair, and damage to the surrounding property and infrastructure. However, these costs can be reduced by minimizing the break detection and location time using a continuous monitoring approach (Misiunas et al., 2005), in other words, by leakage control.

According to Duzinkiewicz et al. (2008), this monitoring, or leakage control, is one of the most important steps in the advanced control of complex dynamical systems, as water distribution systems. For this, monitoring of leakages involves dividing the distribution system into well-defined areas that each can be supplied through a single pipe where a flow meter capable of measuring low flow rates is installed. These areas are known as district metering areas or DMAs (Hunaidi et al., 2004).

\subsection{Multi-Criteria Decision Aid (MCDA)}

In recent decades, several Multi-Criteria Decision Aid (MCDA) methods have been proposed to help us in selecting the best compromise alternatives (Behzadian et al., 2010). It is because MCDA methods provide efficient tools to deal with operations research problems with more than one criterion (Abrishamchi et al., 2005). These methods can be divided into two main categories according to the rationality of the decision maker for the aggregation procedure: (1) non-compensatory, and (2) compensatory.

In the methods that are based on non-compensatory aggregation procedure, a loss of an alternative on a criterion cannot be compensated by the gain of this alternative on other criteria (Del Vasto-Terrientes et al., 2015). In this approach, it can highlight the methods of ELECTRE families (Elimination and Choice Expressing Reality) (Roy \& Bertier, 1973) and PROMETHEE family (Preference Ranking Organization Method for Enrichment Evaluations) (Belton \& Stewart, 2002). According Macharis et al. (2004), these methods do not provide specific guidelines to determine the weights of the criteria. In fact, they assume that the decision maker is able to weigh the criteria appropriately, at least, when the number of criteria is not very large. This point can hinder the process difficulty of the decision maker express their preferences in an intuitive way.

On the other hand, in compensatory methods the evaluation of an alternative consider the trade-offs between the criteria (Almeida, 2011). In this approach, it can highlight some methods, such as: MAUT (Multi-Attribute Utility Theory) (Keeney \& Raiffa, 1976), MACBETH (Measuring Attractiveness by a Categorical Based Evaluation Technique) (Bana e Costa \& Vansnick, 1994), SMARTS (Simple Multi-Attribute Rating Technique), SMARTER (Simple Multi-Attribute Rating Technique Extended to Ranking) (Edwards \& Hutton, 1994) and AHP (Analytic Hierarchy Process) (Saaty, 1980). These methods consider a value function $v_{\mathrm{j}}\left(a_{\mathrm{i}}\right)$ for each criterion $j$ to obtain the global value function $V\left(a_{i}\right)$ (Almeida, 2013), i.e., the global value of alternative ' $a_{i}$ '.

In this sense, MAUT incorporates the utility theory the issue of treatment of problems with multiple attributes. For each viable alternative from a set of feasible alternative is associated a consequence of which are related $m$ attributes. The problem is to establish a utility function $u$ defined on the space of consequences (Keeney \& Raiffa, 1976). The AHP and MACBETH methods perform a pairwise comparison procedure between alternatives for each criterion. These use semantic scale for evaluations, considering that there may be hesitation from decision maker in evaluating the alternatives into quantitative values (Almeida, 2011). Finally, Edwards \& Hutton (1994) proposed the SMARTS method as a simplified version of MAUT. It uses linear approximations of functions of one-dimensional utility, an additive aggregation model and swing weights. The SMARTER method is based on SMARTS, but is even simpler to use.

\section{The proposed decision model to control water losses}

The quantification, detection, pressure management and monitoring alternatives to control water losses are considered in this paper as preventive measures to control water losses because it is from these actions that a water company is able to take corrective measures when losses are detected. Thus, the proposed model helps the decision maker to evaluate a portfolio of preventative actions to efficient control water losses in urban water supplies networks. These actions relate to both physical and nonphysical losses.

To solve this type of the problem, there is, in the literature, the PROMETHEE V method. It considers a combination of a non-compensatory nature of the evaluation of alternatives among criteria and presents as result a portfolio of alternatives based 
on integer linear programming (Fontana \& Morais, 2013). However, in case shown here, the DM believes that there is a degree of compensation between the considered attributes.

In other words, according to the decision maker (DM), a bad evaluation of an alternative on one criterion, or attribute, can be compensate for a good evaluation on another attribute. Thus, it is considered that there could be trade-offs between the attributes, which requires the application of specific methods of decision-making, such as non-compensatory methods. Therefore, the PROMETHEE $\mathrm{V}$ method is not appropriated to be applied for this evaluation of alternatives.

Moreover, due to the characteristics of the problem, the SMARTER method was chosen for this study. It is because this method simplifies the assumptions in the analysis process. As mentioned before, it uses a procedure called 'swing weights' to obtain a constant scale and considers linear function values for intra-criterion evaluation (Almeida, 2013). According to Fontana et al. (2011), it is highly important to develop a simple and easy decision making model to use and understand the procedures, particularly when the DM has no knowledge of the multi-attribute decision aid approach

Therefore, the proposed model is divided into two basics phases: (1) multi-attribute value approach (SMARTER method) and (2) Integer Linear Programming. In Figure 1 each step of the proposed model is shown.

\subsection{Step 1: problem characterization}

The preliminary step in the decision making process is the survey of alternatives. In this stage, the DM should be asked which preventive actions of water loss control are available. It is important that the DM is knowledgeable of all the alternatives surveyed, able to analyze them within the proposed framework and has experience with automation, data registration and networks maintenance. Therefore, the preventive actions raised in this study were following:

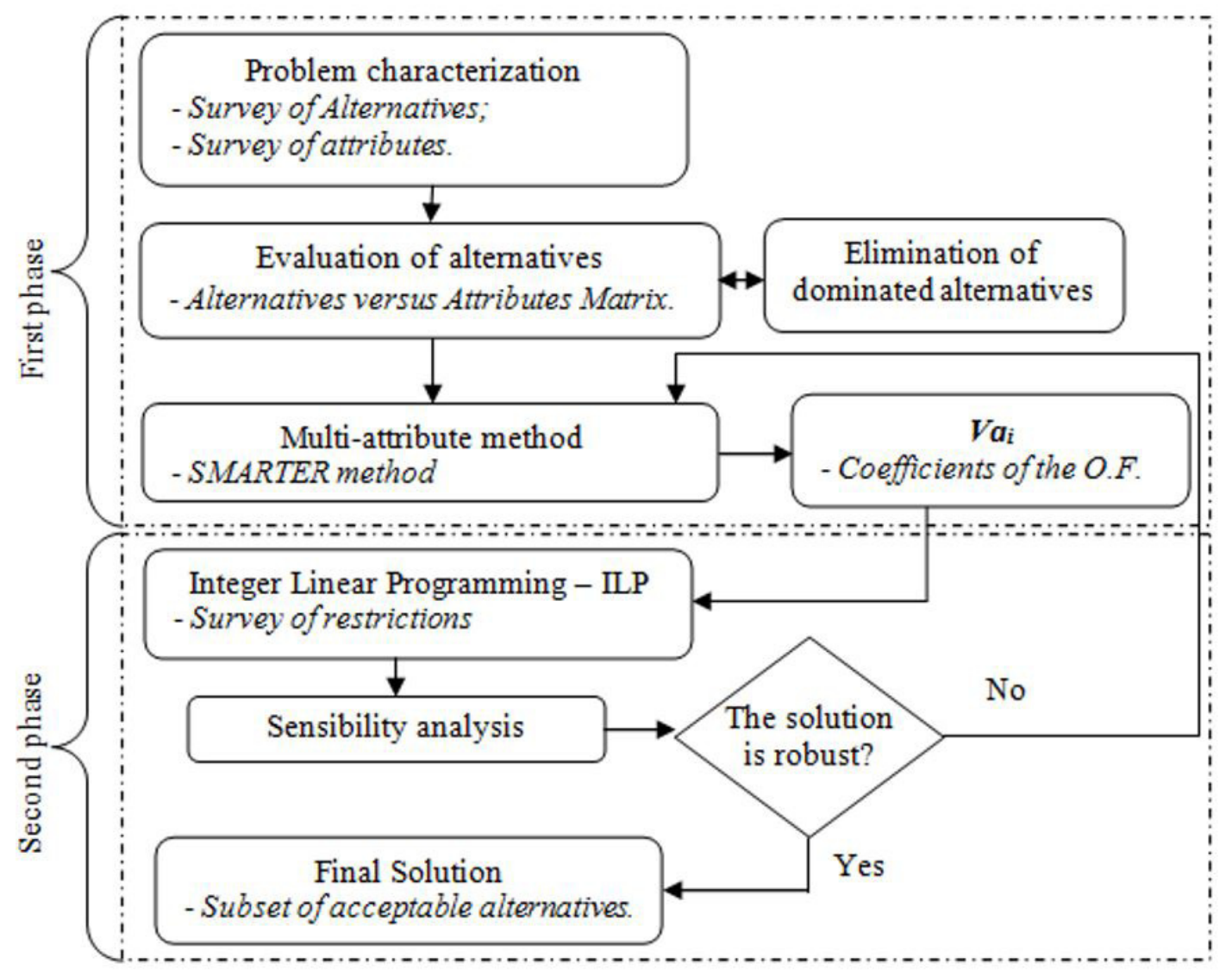

Figure 1. Steps of the proposed model. 
- Alternative $\left(a_{1}\right)$. Use of equipment, instruments and apparatus that systematically sweep the supply network to identify (detect) leaks: $a_{11}$ - Geophone electronic; $a_{12}$ - Electronic listening rods; $a_{13}$ - Thermal sensors; $a_{14}$ - Injection of tracer dyes; $a_{15}$ - Injection of tracer gases.

- Alternative $\left(a_{2}\right)$. Education on the efficient use of water, which shows how to save water inside and outside the home, and encourage people to make reports of visible leaks to expedite the maintenance process and avoid excessive water loss: $a_{21}$ - Advertising campaigns; $a_{22}$ - Educational campaigns in schools.

- Alternative $\left(a_{31}\right)$. Fraud Audit: A measure aimed at losses that occur with the illegal use of water from end users (illegal connection, reversal of the hydrometer and violation of the hydrometer).

- Alternative $\left(a_{41}\right)$. Segmentation network and / or installation of pressure reducing valves, including the deployment of valves and pressure macro-meter areas.

- Alternative $\left(a_{5}\right)$. Implementation and maintenance of a continuous monitoring system of the network is ideal in cases where the use of the alternatives ' $a_{1}$ ' are difficult to apply, either for operational reasons, or because environmental issues. $a_{51}$ - Data logger; $a_{52}$ - Tubo de pilot; $a_{53}$ - Thermographic Camera System; $a_{54}-$ Automation System.

- Alternative $\left(a_{6}\right)$. Using indicators to quantify the losses: important information for the planning of actions needs to be taken to control losses. $a_{61}-24$ hours Zone Measuring (HZM); $a_{62}$ - Minimum Night Flow Analysis (MNF).

- Alternative $\left(a_{71}\right)$. Visual inspection to detection of apparent physical losses.

- Alternative $\left(a_{8}\right)$. Alternatives employed to combat sub-metering consumption. $a_{81}$. Calibration of hydrometers; $a_{82}$. Implantation and/or replacement of the hydrometers.

After that, the DM is asked which attributes should be considered in the evaluation of preventive actions for loss control in the water supply system. The attributes raised in this study were the following:

- $A t_{1}$ - Total cost of alternative implementation (in dollars);

- $\mathrm{At}_{2}$ - Efficiency of the alternative in control losses. This attribute is evaluated according to the following semantic scale: (4) Very high, (3) High, (2) Regular, (1) Low; (0) Very low.

- $\mathrm{At}_{3}$ - Time needed to produce a first effective result by alternative choice (measured in months).

- $\mathrm{At}_{4}$ - Potential reduction in waste water, i.e., it reflects the potential of the alternative to reduce the water used irrationally, preferably in systems with collapse in supply or that are subsidized. The semantic scale used in this evaluation is: (4) Very high, (3) High, (2) Regular, (1) Low; (0) Very low or inefficient.

- $\mathrm{At}_{5}$ - Evaluates the need to hire skilled labor to implement the action. The assessment of this attribute is made according to the following classification: (2) Good - There are trained personnel in the company to perform the action; (1) Regular - The company needs to train their team to perform the action; (0) Bad - The company needs to hire trained personnel or outsource to another company specializes.

- $\mathrm{At}_{6}$ - Lifetime of the alternative, i.e., the period where the alternative will generate results in loss control (measured in months).

The DM wants to obtain low values for attributes $A t_{1}$ and $A t_{3}$, i.e., minimization of the evaluation in these attributes, while the other attributes should be maximized.

\subsection{Step 2: evaluation of dominated alternatives}

Following the model, the evaluation of alternatives is performed on each attribute. The alternatives that are dominated by the others must be eliminated. Given a set of alternatives $A$, such that $A=\left\{a_{1}, a_{2}, \ldots, a_{\mathrm{i}}\right\}$, the alternative $a_{\mathrm{i}}$ is considered dominated when all other alternatives in $A$ are better than $a_{\mathrm{i}}$ on at least one criterion and, at the same time, all other alternatives in $A$ are as good as $a_{\mathrm{i}}$ in all other criteria. In the case analyzed there are not dominated alternatives. Table 1 shows the matrix of alternatives versus attributes.

Table 1. Matrix evaluation: alternative $v s$ attribute.

\begin{tabular}{cllllll}
\hline Alternatives & At1 & At2 & At3 & At4 & At5 & At6 \\
\hline$a_{11}$ & 0.14 & 1.00 & 1.00 & 0.50 & 0.50 & 1.00 \\
$a_{12}$ & 0.62 & 0.50 & 0.80 & 0.50 & 0.50 & 0.80 \\
$a_{13}$ & 0.29 & 0.50 & 0.93 & 0.25 & 0.00 & 0.60 \\
$a_{14}$ & 0.82 & 0.25 & 0.40 & 0.25 & 1.00 & 0.13 \\
$a_{15}$ & 0.90 & 0.00 & 0.40 & 0.25 & 1.00 & 0.20 \\
$a_{21}$ & 0.23 & 1.00 & 0.53 & 1.00 & 0.00 & 0.00 \\
$a_{22}$ & 1.05 & 0.25 & 0.20 & 0.75 & 0.50 & 0.00 \\
$a_{31}$ & 1.00 & 0.75 & 0.93 & 1.00 & 1.00 & 0.20 \\
$a_{41}$ & 0.36 & 0.75 & 0.40 & 0.00 & 1.00 & 1.00 \\
$a_{51}$ & 0.68 & 0.25 & 0.13 & 0.00 & 0.00 & 0.60 \\
$a_{52}$ & 0.86 & 0.25 & 0.00 & 0.00 & 0.50 & 0.47 \\
$a_{53}$ & 0.73 & 0.50 & 0.40 & 0.00 & 0.00 & 0.60 \\
$a_{54}$ & 0.00 & 1.00 & 1.00 & 0.25 & 0.00 & 1.00 \\
$a_{61}$ & 1.14 & 0.50 & 0.40 & 0.00 & 0.50 & 0.20 \\
$a_{62}$ & 1.09 & 1.00 & 0.53 & 0.00 & 0.50 & 0.20 \\
$a_{71}$ & 1.00 & 0.50 & 0.00 & 0.00 & 1.00 & 0.20 \\
$a_{81}$ & 0.95 & 0.50 & 0.40 & 0.75 & 0.50 & 0.00 \\
$a_{82}$ & 0.68 & 0.75 & 0.80 & 0.75 & 1.00 & 0.20 \\
\hline & & & & & &
\end{tabular}




\subsection{Step 3: the multi-attribute value method - SMARTER}

The SMARTER method requires that the decision-making model meet the linearity of the one-dimensional utilities for each attribute and the property of the additive independence, in other words, it checks if the values assigned to each alternative on a given attribute are not linked to the values of preferences on other attributes (Valois \& Almeida, 2009). Once the DM preferences behave linearly on the attributes and additive independence was checked, the additive model can be used.

In this way, in the SMARTER method, the attributes are compensatory, so it is necessary that the evaluations of alternatives versus attributes (step 2) be all on the same measurement scale. For this reason, it converts the values of the alternatives to a range between 0 and 1 , where 0 is the worst alternative and 1 the best alternative in each attribute, if its goal is to maximize or minimize (Fontana \& Morais, 2015). Thus, there are basically three normalization procedures, as in Equations 1-3.

$v_{\mathrm{j}}^{\mathrm{j}}\left(a_{\mathrm{i}}\right)=v_{\mathrm{j}}\left(a_{\mathrm{i}}\right) /\left[\operatorname{Max} v_{\mathrm{j}}\left(a_{\mathrm{i}}\right)\right]$

$v_{\mathrm{j}}^{\prime}\left(a_{\mathrm{i}}\right)=\left[v_{\mathrm{j}}\left(a_{\mathrm{i}}\right)-\operatorname{Min} v_{\mathrm{j}}\left(a_{\mathrm{i}}\right)\right] /\left[\operatorname{Max} v_{\mathrm{j}}\left(a_{\mathrm{i}}\right)-\operatorname{Min} v_{\mathrm{j}}\left(a_{\mathrm{i}}\right)\right]$

$v_{\mathrm{j}}^{\prime}\left(a_{\mathrm{i}}\right)=v_{\mathrm{j}}\left(a_{\mathrm{i}}\right) /\left[\sum_{\mathrm{i}} v_{\mathrm{j}}\left(a_{\mathrm{i}}\right)\right]$

According de Almeida (2013), the procedures (1) and (3) maintain the proportionality, but it does not in the procedure (2). Moreover, the use of different scales on the same problem can lead to inconsistencies in the final solution by the SMARTER method. Therefore, it is important to adopt the same procedure to normalize the evaluations in all criteria. In this sense, a qualitative scale evaluated the attributes $A t_{2}, A t_{4}$ and $A t_{5}$, where the values were placed into an interval scale; thus, the procedure (2) must to be preferred. Table 1 showed the values standardized by this procedure.

Subsequently, the values of the constant scale are elicited from the DM by 'swing weights' procedure. For this, the DM answers several questions, such as (Fontana et al., 2011): "If there is an alternative that had the worst score for all attributes examined, given the opportunity to exchange the evaluation in only one dimension, to change from the worst to the best value among the alternatives, which dimension would you improve?" The DM then responds with attribute ' $y$. This process is continued until all dimensions are ranked (Fontana \& Morais, 2015).
Thus, from the 'swing weights', the proposed problem has the following ranking of the attributes: $A t_{2} \succ A t_{1} \succ A t_{6} \succ A t_{4} \succ A t_{3} \succ A t_{5}$. After that, the SMARTER method uses predetermined values for the constant scale, called 'Rank Order Centroid weights' (ROC). Edwards \& Hutton (1994) reported very little loss of precision in determining the value of the constant scale. They stated for a decision based on these constant scales, the SMARTER method is in 98-99\% agreement with values obtained from a complete survey of constant scale.

Then, given $m$ attributes, such that $j=\{1,2,3, \ldots, m\}$, and a ranking of these attributes determined by the DM from the previous procedure, equal to $w_{1} \succ w_{2} \succ w_{3} \succ \ldots \succ w_{\mathrm{m}}$, the constant scales of the ROC curve are calculated as in Equation 4 (Fontana \& Morais, 2015).

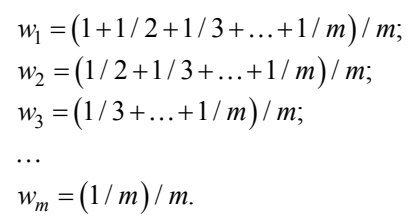

It can be observed that the sum of constant scales should be as in Equation 5 .

$$
\sum_{j=1}^{m} w j=1
$$

Therefore, in this case, the constant scales from the ROC curve are: $w_{2}=0.4083 ; w_{1}=0.2417$; $w_{6}=0.1583 ; w_{4}=0.1028 ; w_{3}=0.0611 ; w_{5}=0.0278$. Moreover, the SMARTER method comprises the sum of the relationships between the evaluations of alternatives along with the constant scales of each attribute. Thus, to an alternative $a_{11}$, the expression used for the global value $\left(\mathrm{Va}_{\mathrm{i}}\right)$ is as in Equation 6.

$$
\begin{aligned}
& V a_{11}=0.4083 v_{a 11}\left(x_{a 11 A t 2}\right)+0.2417 v_{a 11}\left(x_{a 11 A t 1}\right)+ \\
& 0.1583 v_{a 11}\left(x_{a 11 A t 6}\right)+0.1028 v_{a 11}\left(x_{a 11 A t 4}\right)+ \\
& 0.0611 v_{a 11}\left(x_{a 11 A t 3}\right)+0.0278 v_{a 11}\left(x_{a 11 A t 5}\right)
\end{aligned}
$$

To sum up, Table 2 shows the result from the application of the SMARTER method on the water loss problem reported here.

\subsection{Step 4: Integer Linear Programming (ILP)}

Every water supply company presents some operational restrictions. The main constraint encountered in any company is with regard to resource availability for the adoption of preventive maintenance measures. Additionally, it does not make sense to adopt certain measures simultaneously, (e.g., two instruments for leak detection). The constraints must be surveyed from 
Table 2 . The alternative utility by SMARTER.

\begin{tabular}{cccccc}
\hline Rank & Alternatives & $\mathrm{Va}_{\mathrm{i}}$ & Rank & Alternatives & $\mathrm{Va}_{\mathrm{i}}$ \\
\hline $1^{\circ}$ & $a_{31}$ & 0.74 & $9^{\circ}$ & $a_{12}$ & 0.47 \\
$2^{\circ}$ & $a_{11}$ & 0.73 & $10^{\circ}$ & $a_{22}$ & 0.46 \\
$3^{\circ}$ & $a_{62}$ & 0.72 & $11^{\circ}$ & $a_{41}$ & 0.45 \\
$4^{\circ}$ & $a_{82}$ & 0.62 & $12^{\circ}$ & $a_{53}$ & 0.40 \\
$5^{\circ}$ & $a_{21}$ & 0.60 & $13^{\circ}$ & $a_{14}$ & 0.38 \\
$6^{\circ}$ & $a_{81}$ & 0.55 & $14^{\circ}$ & $a_{13}$ & 0.36 \\
$7^{\circ}$ & $a_{61}$ & 0.52 & $a_{52}$ & 0.32 \\
$7^{\circ}$ & $a_{71}$ & 0.52 & $15^{\circ}$ & $a_{15}$ & 0.30 \\
$8^{\circ}$ & $a_{54}$ & 0.50 & $17^{\circ}$ & $a_{51}$ & 0.28 \\
\hline
\end{tabular}

DM. Thus, for the problem studied, the following integer linear programming problem arises:

Objective Function:

$$
\begin{aligned}
& \operatorname{Max} Z=0.73 a_{11}+0.47 a_{12}+0.36 a_{13}+0.38 a_{14}+ \\
& 0.30 a_{15}+0.60 a_{21}+0.46 a_{22}+0.74 a_{31}+0.45 a_{41}+ \\
& 0.28 a_{51}+0.32 a_{52}+0.40 a_{53}+0.50 a_{54}+0.52 a_{61}+ \\
& 0.72 a_{62}+0.52 a_{71}+0.55 a_{81}+0.62 a_{82} \geq 0
\end{aligned}
$$

Subject to:

$$
\begin{aligned}
& 120 a_{11}+67 a_{12}+103 a_{13}+45 a_{14}+36 a_{15}+ \\
& 110 a_{21}+20 a_{22}+25 a_{31}+95 a_{41}+60 a_{51}+40 a_{52}+ \\
& 55 a_{53}+135 a_{54}+10 a_{61}+15 a_{62}+25\left(a_{71}-a_{31}\right)+ \\
& 30 a_{81}+60 a_{82} \leq 550 \\
& a_{11}+a_{12}+a_{13}+a_{14}+a_{15} \leq 1 \\
& a_{51}+a_{52}+a_{53}+a_{54} \leq 1 \\
& a_{61}+a_{62} \leq 1 \\
& a_{11}, a_{12}, a_{13}, a_{14}, a_{15}, a_{21}, a_{22}, a_{31}, a_{41}, a_{51}, a_{52}, a_{53}, \\
& a_{54}, a_{61}, a_{62}, a_{71}, a_{81}, a_{82}=[0,1]
\end{aligned}
$$

The coefficients of the objective function (7) are associated with the global value $\left(\mathrm{Va}_{\mathrm{i}}\right)$ obtained from SMARTER method (Table 2). Restriction of Equation 8 concerns the availability of funds for implementation of actions (in $\$ 1,000.00$ ). Alternatives $a_{31}$ and $a_{71}$ can be performed by the same team, having the same total cost when intercropped. Therefore, for the selection of both, the cost should be counted only once. This is guaranteed in Equation 8 by $\left(a_{71}-a_{31}\right)$; restriction of Equation 9-11 ensures that only one alternative group $a_{1}, a_{5}$ and $a_{6}$ is adopted, respectively because they are direct replacements; restriction of Equation 12 ensures that the value of the variables is zero or one.
Considering only the ordering from Table 2 of the alternatives selected and noting only the available cost restriction, they would be: $a_{11}, a_{21}, a_{31}, a_{54}, a_{61}$, $a_{62}, a_{71}, a_{81}$ and $a_{82}$. These alternatives have a total implementation cost of $\$ 505,000.00$ and a sum of values equal to $Z=5.50$. However, as observed in constraint (11), it does not make much sense to have alternatives $a_{61}$ and $a_{62}$ in the same subset of actions. Removing one of the two, it cannot hold the next alternative in the rank $\left(a_{12}\right)$; therefore, it violates constraint (8).

However, when applied to integer linear programming, the solution to the problem is the following subset: $a_{11}, a_{21}, a_{22}, a_{31}, a_{41}, a_{53}, a_{62}, a_{71}, a_{81}$ and $a_{82}$. These alternatives cost a total of $\$ 530,000.00$. Observe that this case accounts for all the constraints and, therefore, the subset is more realistic. The sum of the values of alternatives is $Z=5.79$, higher than the previous result.

\subsection{Step 5: sensibility analysis}

To check the robustness of the method, because the SMARTER method is additive and requires trade-offs between the attributes to be evaluated, a simulation was performed on all the attributes that were equally important to the DM. In the first stage of SMARTER, the ranks changed, and in the second phase, the subset of admissible solutions remained the same. Therefore, it was noted that the ROC weights are representative of the DM's preferences regarding the ranking of attributes in selecting the portfolio of preventive maintenance alternatives for the water distribution network.

In case of a change in the solution, during the sensibility analysis, a new process of elicitation of the importance of the attributes must be performed to ensure that the solution represents the preferences of the DM (Step 3 of the model). 


\section{Concluding remarks}

This paper presented a decision model integrating a multi-attribute value method, SMARTER method, with an integer linear programming approach. The objective of the model is to analyze a subset of available actions for water loss control in the urban water supply, and determine which of them should be adopted, taking into account the characteristics of each alternative. Alternatives were evaluated by their attributes and restrictions on their deployment. It showed that the proposed method is efficient, as it was able to select a subset of viable alternatives (portfolio) to be deployed for water loss control that was representative of the DM' preferences.

Moreover, the integer linear programming disallows negative values in coefficients when the objective function is maximized, which is another advantage of the proposed model in cases of a compensatory rationality, because the SMARTER method does not yield negative values. Finally, the SMARTER calculations are simpler, especially if one takes into account a large set of alternatives to analyze.

DMs are prone to commit errors when the problem under analysis becomes more complex. Therefore, the proposed model can help DMs analyze alternatives and is especially useful when the number of alternatives is high, and there are various compensatory attributes (in the opinion of DM). Additionally, the proposed model still considers restrictions on the implementation of alternatives. Future work includes the application of this methodology in a real-world case study.

\section{References}

Abrishamchi, A., Ebrahimian, A., Tajrishi, M., \& Mariño, M. A. (2005). Case study: application of multicriteria decision making to urban water supply. Journal of Water Resources Planning and Management, 131(4), 326-335. http://dx.doi. org/10.1061/(ASCE)0733-9496(2005)131:4(326).

Abu-Shams, 1., \& Rabadi, A. (2003). The strategy of restructuring and rehabilitating the greater amman water network. International Journal of Water Resources Development, 19(2), 173-183. http://dx.doi.org/10.1080/0790062032 000089301.

Almeida, A. T. (2011). O conhecimento e o uso de métodos multicritério de apoio a decisão. Recife: Editora Universitária da UFPE.

Almeida, A. T. (2013). O processo de decisões nas organizações: construindo modelos decisão multicritério. São Paulo: Atlas.

Araral, E., \& Wang, Y. (2013). Water demand management: review of literature and comparison in South-East Asia. International Journal of Water Resources Development, Special lssue: Urban water management: public-private participation and water pricing, 29(3), 434-450. http:// dx.doi.org/10.1080/07900627.2013.826413.

Arreguin-Cortes, F., \& Ochoa-Alejo, L. (1997). Evaluation of water losses in distribution networks. Water Resources
Planning and Management, 123, 284-291. http://dx.doi. org/10.5829/idosi.wasj.2012.18.04.1246.

Bana e Costa, C. A., \& Vansnick, J. C. (1994). MACBETH: an interactive path towards the construction of cardinal value functions. International Transactions in Operational Research, 1(4), 489-500. http://dx.doi.org/10.1016/09696016(94)90010-8.

Behzadian, M., Kazemadeh, R. B., Albadvi, A., \& Aghdasi, M. (2010). PROMETHEE: a comprehensive literature review on methodologies and applications. European Journal of Operational Research, 200, 198-215. http://dx.doi. org/10.1016/j.ejor.2009.01.021.

Belton, V., \& Stewart, T. J. (2002). Multiple criteria decision analysis. Berlim: Kluwer Academic Publishers.

Buchberger, S. G., \& Nadimpalli, G. (2004). Leak estimation in water distribution systems by statistical analysis of flow readings. Water Resources Planning and Management, 130(4), 321-329. http://dx.doi.org/10.1061/(ASCE)07339496(2004)130:4(321).

Charalambous, B., Foufeas, D., \& Petroulias, N. (2014). Leak detection and water loss management. Water Utility Journal, 8, 25-30. Retrieved in 11 December 2015, from http://www.ewra.net/wuj/issue_8.htm

Covas, D., Ramos, H., \& Almeida, A. B. (2005). Standing wave difference method for leak detection in pipeline systems. Journal of Hydraulic Engineering, 131, 1106-1116. http:// dx.doi.org/10.1061/(ASCE)0733-9429(2005)131:12(1106).

Del Vasto-Terrientes, L., Valls, A., Slowinski, R., \& Zielniewicz, P. (2015). ELECTRE-111-H: an outranking-based decision aiding method for hierarchically structured criteria. Expert Systems with Applications, 42, 4910-4926. http://dx.doi. org/10.1016/j.eswa.2015.02.016.

Duzinkiewicz, K., Borowa, A., Mazur, K., Grochowski, M., Brdys, M. A., \& Jezior, K. (2008). Leakage detection and localisation in drinking water distribution networks by multiregional PCA. Studies in Informatics and Control, 17, 135-152. Retrieved in 11 December 2015, from http://sic. ici.ro/?page_id=441.

Edwards, W., \& Hutton, B. F. (1994). SMARTS and SMARTER: improved simple methods for multiattribute utility measurement. Organizational Behavior and Human Decision Processes, 60, 306-325. http://dx.doi.org/10.1006/obhd.1994.1087.

Ferrante, M., \& Brunone, B. (2003). Pipe system diagnosis and leak detection by unsteady-state tests. 1. Harmonic analysis. Advances in Water Resources, 26, 95-105. http:// dx.doi.org/10.1016/S0309-1708(02)00101-X.

Fontana, M. E., \& Morais, D. C. (2013). Using promethee V to select alternatives so as to rehabilitate water supply network with detected leaks. Water Resources Management, 27, 4021-4037. http://dx.doi.org/10.1007/s11269-013-0393-1.

Fontana, M. E., \& Morais, D. C. (2015). Segmentation model for water distribution networks based on the characteristics of consumer units. Production, 25(1), 143-156. http://dx.doi. org/10.1590/S0103-65132013005000071.

Fontana, M. E., Morais, D. C., \& Almeida, A. T. (2011). A MCDM model for urban water conservation strategies. In R. H. C. Takahashi, K. Deb, E. Wanner \& S. Greco (Eds.), Evolutionary multi-criterion optimization (Lecture Notes in Computer Science, 6576, pp. 564-578). Heidelberg: Springer. http:// dx.doi.org/10.1007/978-3-642-19893-9_39

Fontanazza, C. M., Freni, G., Loggia, G. L., Notaro, V., \& Puleo, V. (2012). A composite indicator for water meter replacement in an urban distribution network. Urban Water 
Journal, 9(6), 419-428. http://dx.doi.org/10.1080/15730 62X.2012.690434.

Gheisi, A. R., \& Naser, Gh. (2013). On the significance of maximum number of components failures in reliability analysis of water distribution systems. Urban Water Journal, 10(1), 10-25. http://dx.doi.org/10.1080/1573062X.2012.690433.

Giustolisi, O., Savic, D., \& Kapelan, Z. (2008). Pressure-driven demand and leakage simulation for water distribution networks. Journal of Hydraulic Engineering, 134, 626-635. http://dx.doi.org/10.1061/(ASCE)0733-9429(2008)134:5(626).

Holnicki-Szulc, J., Kolakowski, P., \& Nasher, N. (2005). Leakage detection in water networks. Journal of Intelligent Material Systems and Structures, 16, 207-219. http://dx.doi. org/10.1177/1045389X05049169.

Horne, J. (2013). Economic approaches to water management in Australia. International Journal of Water Resources Development, 29(4), 526-543. http://dx.doi.org/10.1080 /07900627.2012.712336.

Hunaidi, 0., \& Wang, A. (2006). A New system for locating leaks in urban water distribution pipes. International Journal of Management of Environmental Quality, 17(4), 450-466. http://dx.doi.org/10.1108/14777830610700928.

Hunaidi, O., Wang, A., Bracken, M., Gambino, T., \& Fricke, C. (2004). Acoustic methods for locating leaks in municipal water pipe networks. In International Water Demand Management Conference, Dead Sea, Jordan. Retrieved in 11 December 2015, from http://citeseerx.ist.psu.edu/ viewdoc/download?doi=10.1.1.6.3793\&rep=rep $1 \&$ type=pdf

Kanakoudis, V., \& Tsitsifli, S. (2014). Using the bimonthly water balance of a non-fully monitored water distribution network with seasonal water demand peaks to define its actual NRW level: the case of Kos town, Greece. Urban Water Journal, 11(5), 348-360. http://dx.doi.org/10.108 0/1573062X.2013.806563.

Keeney, R. L., \& Raiffa, H. (1976). Decision with multiple objectives: preferences and value trade-offs. New York: John Wiley.

Lambert, A. 0. (1994). Accounting for Losses: the bursts and background concept. Water and Environment Journal : the Journal / the Chartered Institution of Water and Environmental Management, 8, 205-214. http://dx.doi. org/10.1111/j.1747-6593.1994.tb00913.x.

Lopez, H. M. L., \& Almeida, A. T. (2013). Project portfolio selection in an electric utility company using PROMETHEE V. Production, 24(3), 559-571. http://dx.doi.org/10.1590/ S0103-65132013005000045.

Macharis, C., Springael, J., Brucker, K., \& Verbeke, A. (2004). PROMETHEE and AHP: the design of operational synergies in multicriteria analysis: strengthening PROMETHEE with ideas of AHP. European Journal of Operational Research, 153, 307-317. http://dx.doi.org/10.1016/S0377-2217(03)00153-X.

McKenzie, R., \& Seago, C. (2005). Assessment of real losses in potable water distribution systems: some recent developments. Water Science and Technology: Water Supply, 5, 33-40. Retrieved in 11 December 2015, from http://ws.iwaponline. com/content/5/1/33.article-info

Mesquita, A. M., \& Ruiz, R. M. (2013). A financial economic model for urban water pricing in Brazil. Urban Water Journal, 10(2), 85-96. http://dx.doi.org/10.1080/15730 62X.2012.699073.

Misiunas, D., Vitkovský, J., Olsson, G., Simpson, A., \& Lambert, M. (2005). Pipeline break detection using pressure transient monitoring. Water Resources Planning and Management, 131, 316-325. http://dx.doi.org/10.1061/(ASCE)07339496(2005) 131:4(316).

Morais, D. C., \& Almeida, A. T. (2007). Group decision-making for leakage management strategy of water network. Resources, Conservation and Recycling, 52, 441-459. http://dx.doi. org/10.1016/j.resconrec.2007.06.008.

Mounce, S. R., Boxall, J. B., \& Machell, J. (2010). Development and verification of an online artificial intelligence system for detection of bursts and other abnormal flows. Water Resources Planning and Management, 136, 309-318. http://dx.doi.org/10.1061/(ASCE)WR.1943-5452.0000030.

Nazif, S., Karamouz, M., Tabesh, M., \& Moridi, A. (2010). Pressure management model for urban water distribution networks. Water Resources Management, 24, 437-458. http://dx.doi.org/10.1007/s11269-009-9454-x.

Nicolini, M., \& Zovatto, L. (2009). Optimal location and control of pressure reducing valves in water networks. Water Resources Planning and Management, 135(3), 178-187. http://dx.doi. org/10.1061/(ASCE)0733-9496(2009)135:3(178).

Puust, R., Kapelan, Z., Savic, D. A., \& Koppel, T. (2010). A review of methods for leakage management in pipe networks. Urban Water Journal., 7, 25-45. http://dx.doi. org/10.1080/15730621003610878.

Roy, B., \& Bertier, P. (1973). La méthode Electre ll: une application au média-planning. In M. Ross (Eds.), OR'72 (pp. 291-302). Amsterdam: North-Holland Publishing Company.

Saaty, T. L. (1980). The analytic hierarchy process. New York: McGraw-Hill.

Tabesh, M., Shirzad, A., \& Arefkhani, A. V. (2014). A comparative study between the modified and available demand driven based models for head driven analysis of water distribution networks. Urban Water Journal, 11(3), 221-230. http:// dx.doi.org/10.1080/1573062X.2013.783084.

Trojan, F., \& Morais, D. C. (2012). Using Electre TRI to support maintenance of water distribution networks. Pesquisa Operacional, 32(2), 423-442. http://dx.doi.org/10.1590/ S0101-74382012005000013.

Valois, U., \& Almeida, A. T. (2009). Support model for multicriteria decision to outsource productive activities based on SMARTS method. Prodution, 19(2), 249-260. http://dx.doi.org/10.1590/S0103-65132009000200003.

Wang, X. J., Lambert, M. F., Simpson, A. R., Liggett, J. A., \& Vítkovský, J. P. (2002). Leak detection in pipelines using the damping of fluid transients. Journal of Hydraulic Engineering, 128(7), 697-711. http://dx.doi.org/10.1061/ (ASCE)0733-9429(2002)128:7(697).

Wu, Z. Y. (2009). Unified parameter optimisation approach for leakage detection and extended-period simulation mode calibration. Urban Water Journal, 6(1), 53-67. http://dx.doi. org/10.1080/15730620802541631.

Wu, Z. Y., Sage, P., \& Turtle, D. (2010). Pressure-dependent leak detection model and its application to a district water system. Water Resources Planning and Management, 136, 116-128. http://dx.doi.org/10.1061/(ASCE)07339496(2010)136:1(116)

Wu, Z. Y., Wang, R. H., Diezo, D., \& Walski, T. (2003). Mining water consumption and GIS-based data for loading water distribution models. In World Water and Environmental Resource Congress (pp. 1-9), Philadelphia, USA. http:// dx.doi.org/10.1061/40685(2003)23. 